Research Article

\title{
Structural and Thermal Analysis of Piston
}

\author{
K.S.Mahajan* and S.H.Deshmukh \\ Mechanical Department, Savitribai Phule Pune University, Pune, India \\ Accepted 15 June 2016, Available online 20 June 2016, Special Issue-5 (June 2016)
}

\begin{abstract}
The objective of the present work is to focus on the structural analysis of ceramic coated piston, working under thermal and mechanical loads. Thermal analysis was carried out on uncoated and ceramic coated piston to verify the temperature changes at the ceramic coated regions using Hypermesh and Ansys. The study of thermal stresses generated due to temperature differences at different materials junctions used in coating was analyzed. The stresses due to the mechanical loads were studied to finally determine the structural behavior of the partially ceramic coated pistons.
\end{abstract}

Keywords: Ceramic Coatings, IC engine, Thermal barrier.

\section{Introduction}

In Internal Combustion (IC) engine, for effective utilization of heat without much heat transfer, the combustion chamber should be insulated. Because of insulation, temperatures reach very high values. Conventional materials cannot withstand such high temperatures in IC engine. Hence, the solution is to use ceramic coatings on the piston, which help to reduce heat transfer and withstand higher temperatures. The life of components is affected due to the presence of high temperatures. The objective of the present work is to focus on the structural analysis of ceramic coated piston, working under thermal and mechanical loads.

\section{Materials}

\subsection{Conventional Piston Materials}

During the early years, cast iron was used as piston material because of its good wear properties, but it has high specific weight, causing increased inertia effects. Later on Aluminum alloy containing silicon came into existence. It helps in the higher strength and reduced expansion. Generally two configurations of Silicon is used in Aluminum alloy. They are eutectic and hypereutectic, containing $12 \%$ and $22 \%$ respectively. If silicon content is more than $12 \%$, the material becomes brittle.

Performance of an engine can be increased by insulating the components of combustion chamber. Due to insulation, the components cannot with stand the higher temperatures resulting in failure. In order to prevent this risk, ceramic coatings are employed which

*Corresponding author: K.S.Mahajan can resist high temperatures to work efficiently as Aluminum alone cannot withstand high temperatures.

\subsection{Ceramic Coatings}

Ceramic Coatings are used as a protective coating on or in between the engine parts, which result in reduction of friction, increase wear resistance and improve heat shielding. All these factors have noticeable influence on the performance parameters and the component life in a vehicle. These coatings help the components to interact in more uniform and compatible fashion. Zirconium based ceramic coatings are widely used. Zirconium along with Magnesia or Yttria has very good mechanical properties, impact and thermal shock resistance. Zirconium-based ceramic coatings are used as thermal barrier coatings owing to their low thermal conductivity and their relatively high coefficients of thermal expansion compared to other ceramics which reduce the detrimental interfacial stresses.

Thermal barrier coatings acts as the insulators on piston surface making it possible to avail more heat for combustion resulting in better work done on piston. These coatings distribute the heat more evenly, which help in preventing high temperatures zones. Keeping more heat on to the piston surface rather than transferring prevents the pre-ignition.

The problem in the combustion chamber with conventional materials is that most of the heat generated in an engine will be lost through heat transfer. Hence, the solution is to make the components insulate and withstand high temperatures in the combustion chamber. By TBCs, burning of gases in an engine can be done more efficiently by raising the temperature of the air-fuel mixture. 
Thermal barrier coatings (TBC) aids in increasing the thermal efficiency of the engine as the heat rejections to surroundings are low with ceramics. The excess heat can be used for improved burning of the air-fuel mixture and reduction in emissions. These coatings have high thermal durability so it is not necessary to cool them immediately like it has to be done for conventional materials. Wear and corrosive properties are very much better than regularly used component materials. Lower heat transfer from the combustion chamber due to coatings helps in using the in-cylinder heat more efficiently. More heat can be transferred to exhaust system. This heat can be used for heat recovery systems for generation of power etc. although installing such heat recovery systems require additional effort. Low thermal conductivity ceramics can be used to control temperature distribution and heat flow in a structure. These coatings also help in reducing the cold start emissions.

Most recent development in the zirconia ceramics are the partially stabilized zirconia (PSZ) and transformation-toughened zirconia. PSZ is reliable, tough and has higher strength than zirconia. Its applications include aerospace coatings, automotive primers and topcoats. PSZ has got thermal expansion coefficient only about $20 \%$ lower than cast iron, so the piston slap problem can be avoided. Its thermal conductivity is about one-third of other ceramics. So due to these factors it can be used for heat engine components. The Transformed - toughened zirconia is much improved form of PSZ, it has higher toughness than that of PSZ.

\section{Literature Review}

F.S Desilva et al. carried out a case study on the fatigue of pistons used in different applications and found, fatigue is not the biggest reason for all the piston damages but it remains a problem as these days more consideration is made into fuel consumption obtained by reduced weight which resulted in the thin walls for the piston and higher stresses

M. Cerit et al. Carried out thermal analysis on partially coated SI engine piston to find the effect of ceramic coatings on the temperatures of crevice and wall quenching regions. The results shown that the temperatures close to the crevice and wall quenching regions where the coatings are done resulted in $100^{\circ} \mathrm{C}$ increase in the temperatures. Due to this increase in the temperatures it is concluded that the air fuel mixture temperature at these regions can be raised and thus unburned charge combustion near the entrance of the clearance was increased.

K. Sridhar, R. Reji Kumar, M. Narasimha Carried out thermal barrier analysis for uncoated Aluminium alloy and ceramic coated Aluminium alloy pistons and found that maximum surface temperature of the ceramic coated piston is increased approximately by $28 \%$ for Zirconium stabilised with magnesium oxide (ZrMg03) coating, 22\% for Mullite coating (3Al2032SiO2) and $21 \%$ for Alumina (Al2O3) than the uncoated Aluminium alloy piston. Ceramic coatings on the piston surface can increase the temperature of the combustion chamber due to the insulation property of the coatings. The thermal strength of the base metal can also be improved. This increase in the combustion chamber temperature of the engine results in the improved thermal efficiency.

\section{Modelling of Piston}

The ceramic coatings (TBC's) were made by removing few millimetres of the piston material on the crown at the edges.

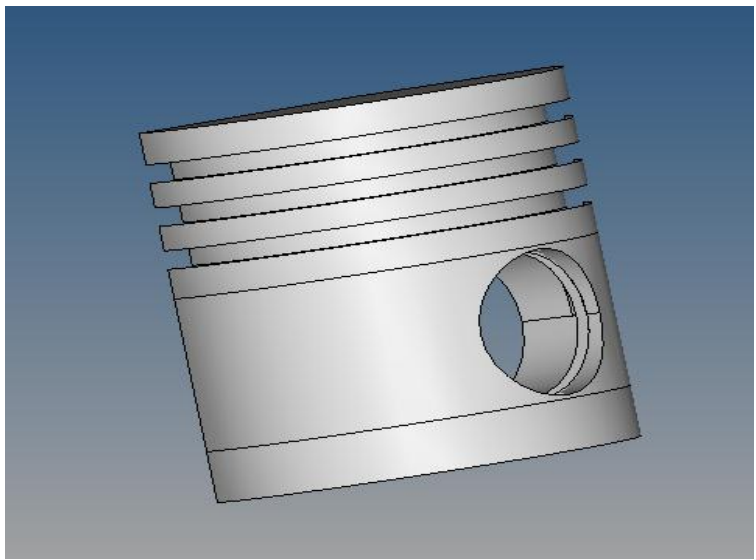

Fig.1 Modelling of piston

Table 1 Piston specifications

\begin{tabular}{|c|c|}
\hline Engine Displacement & $2.5 \mathrm{~L}$ \\
\hline Bore & $9 \mathrm{~mm}$ \\
\hline Power & 89.5 Kw@4600 rpm \\
\hline Torque & 197 Nm@4600 rpm \\
\hline Compression ratio & 8.3:1 \\
\hline
\end{tabular}

\subsection{Meshing of piston}

The meshing of the model is carried out in Hypermesh. The model was first checked for free edges and geometry clean-up was done. Three different materials were present in the piston. The material properties of 3 materials of the piston are indicated in the Table. The uncoated piston with 3D tetra mesh is shown in Figure

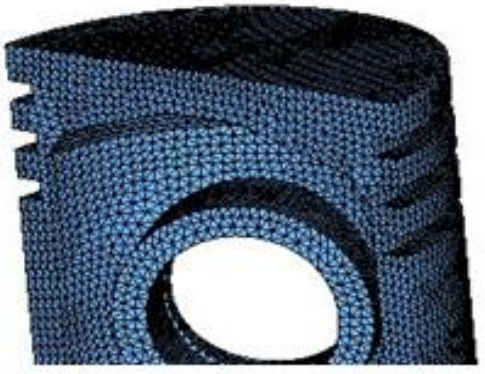

Fig.2 Meshed model of uncoated Piston 
Table 2 Meshed model of uncoated Piston

\begin{tabular}{|c|c|}
\hline Element size & 1.8 \\
\hline No of elements & 52077 \\
\hline No of nodes & 13353 \\
\hline Type of element & tetra4 \\
\hline
\end{tabular}

The connectivity is to be made among the elements of all the materials for proper results. Tetra Mesh had been used for all the four models that need to be analysed. In between the ceramic coating (CC) and the Piston material (Al-Si) Bond Coat (Ni-Cr-Al) was introduced.

Table 3 Material Properties of different materials in piston

\begin{tabular}{|c|c|c|c|}
\hline Property & MgZrO3 & $\begin{array}{c}\text { AlSi } \\
\text { alloy }\end{array}$ & NiCrAl \\
\hline Young's Modulus(MPa) & 46000 & 69000 & 90000 \\
\hline Poisson's ratio & 0.20 & 0.33 & 0.27 \\
\hline $\begin{array}{c}\text { Thermal } \\
\text { Conductivity }\left(\mathrm{W} / \mathrm{mm}^{0} \mathrm{C}\right)\end{array}$ & 0.0008 & 0.155 & 0.016 \\
\hline $\begin{array}{c}\text { Thermal expansion } \\
\text { coefficient }\left(1 /{ }^{0} \mathrm{C}\right)\end{array}$ & 8 & 21 & 12 \\
\hline Density (Ton $/ \mathrm{mm} 3)$ & $\begin{array}{c}5.6 \\
\mathrm{E}-09\end{array}$ & $\begin{array}{c}2.7 \\
\mathrm{E}-09\end{array}$ & $\begin{array}{c}7.8 \\
\mathrm{E}-09\end{array}$ \\
\hline Specific heat $\left(\mathrm{J} / \mathrm{kg}^{0} \mathrm{C}\right)$ & 650 & 960 & 764 \\
\hline
\end{tabular}

The half part of the piston was taken because of the symmetry in geometry, loading and boundary conditions and thus reduction in simulation time was achieved. The piston models with different ceramic coating thickness were meshed. The NiCrAl alloy with constant thickness of $0.15 \mathrm{~mm}$ is used as a bond coat in between the piston base metal and the ceramic coating materials to reduce thermal shock.

\subsection{Mesh Procedure}

The first step is to create a surface mesh for all the 3 materials individually. Tetra mesh was used due to time constraint, with more number of elements to approximately match the accuracy of the hex mesh. After the 2D meshing, the mesh should be checked for quality by considering Jacobian, aspect ratio and connectivity etc., The model should also be checked for free edges and should be deleted if any are present before carrying out 3D tetra mesh.

After meshing the 3D model, the model has to be checked for elemental quality. If the elements fail in quality check more than the permissible amount, it will have its effect in the post processing results. Different entity sets were created to ease the load application in ANSYS. As the piston is a complex structure, SOLID 90 was chosen for the thermal analysis as it is higher order 3-D element type with 20 nodes with Single DOF, temperature at each node. Its equivalent element for structural analysis is SOLID 186. The lower order elements doesn't give proper evaluation as that of higher order elements due to their linearity.
Element size was chosen as 0.9 to capture the fillets and even small radius. Material properties and the element type were assigned in Hypermesh. This meshed piston model was assigned boundary conditions for further analysis, which are discussed in the next section. The model of ceramic coated piston with tetra mesh is shown in Figure

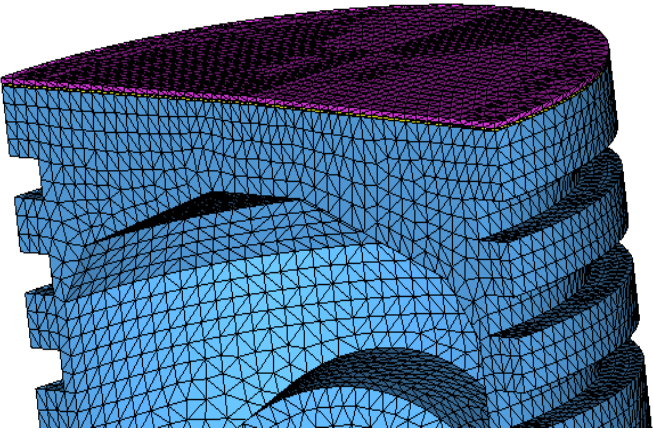

Fig.3 Meshed Model of Ceramic coated piston

\subsection{Boundary Conditions used for the analysis}

The accuracy of the results for the finite element simulations depends upon the boundary conditions assigned. These boundary conditions are the interaction of structure with surroundings. The application of boundary conditions was done in ANSYS by creating the entity sets in Hypermesh, hence the forces can be applied with ease. The model has been discretised based on symmetry boundary condition. Total number of elements in each model divided with symmetry were nearly in and around 50,000. First, a thermal analysis was carried out.

\section{Thermal boundary conditions}

The mode of heat transfer from piston to surroundings is assumed as convection. The heat transfer coefficient, bulk temperature of the surrounding fluid and the temperatures at the piston rings act as the boundary conditions for the thermal analysis. The heat transfer coefficients were calculated and the bulk temperature of the surrounding fluids were assumed based on literature review.

The heat transfer coefficient at the ring lands and the skirt

The heat transfer coefficient at the ring lands and the skirt are calculated by using the formula

$\mathrm{h}=8.235(K / D h)$

$\mathrm{K}$-Thermal Conductivity

Dh - Hydraulic Diameter

The heat transfer coefficient was calculated by considering it as a case of flow of the gases through the annular area between the OD of the ring and the cylinder 


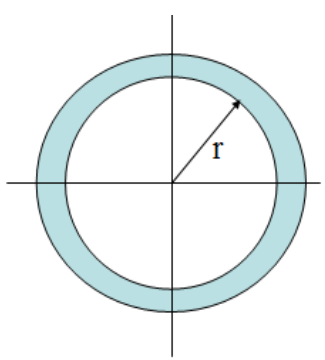

Fig.4 Representation of flow between Piston ring and cylinder wall

Hydraulic diameter (Dh) was calculated by formula

$\mathrm{Dh}=4 \mathrm{~A} / \mathrm{P}$

A- area of flow passage

$\mathrm{P}$ - wet perimeter

Here area of flow passage $(A)=2 \Pi r^{*}(2 b)$

$2 \mathrm{~b}$ - width of the annular ring $=0.05$ inch (assumed)

$\mathrm{P}$ is equal to $2^{*}(2 \Pi r)$ twice the perimeter because both the inner and outer perimeters are part of wetted area.

Therefore, $\mathrm{Dh}=4 * 2 \Pi \mathrm{r} *(2 \mathrm{~b}) / 2 *(2 \Pi \mathrm{r})=4 \mathrm{~b}$

$\mathrm{h}=8.235\left(0.145 /\left(4 * 6.35 e^{-4}\right)\right)$

$=470 \mathrm{~W} / \mathrm{m}^{20} \mathrm{C}$

The heat transfer coefficient at the Crown

The heat transfer coefficient at the Crown was calculated using the formula

$\mathrm{hC}=226.6 P^{0.8} T^{-0.4}(\mathrm{Vp}+1.4)^{0.8}$

$\mathrm{T}$ - Temperature of fluid around the Crown $=650^{\circ} \mathrm{C}$

$\mathrm{P}$ - Maximum pressure in bar

$\mathrm{Vp}$ - Mean piston speed

Piston speed $=$ Number of inlet valves $\times$ Port (Inlet seat diameter/Bore Diameter)2

No. of inlet valves $n=2$

Assumed port velocity $\mathrm{Vs}=30 \mathrm{~m} / \mathrm{s}$

Valve diameter to bore ratio $=0.44$

$\mathrm{Vp}=11.616 \mathrm{~m} / \mathrm{s}$

$\mathrm{h}=226.68^{0.8} 650^{-0.4}(11.616+1.4)^{0.8}$

$=698.06 \mathrm{~W} / \mathrm{m}^{20} \mathrm{C}$

Heat Transfer coefficient under the crown

Heat Transfer coefficient under the crown is given by

$\mathrm{H}_{\mathrm{UC}}=900(N / 4600)^{0.35}$

$$
\begin{aligned}
\mathrm{N} & =\text { Speed in RPM at maximum power } \\
& =4600 \mathrm{rpm} \\
& =900 \mathrm{~W} / \mathrm{m}^{20} \mathrm{C}
\end{aligned}
$$

Heat Transfer coefficient at the inner region of the Skirt

$\mathrm{hS}=240(N / 3600)^{0.35}$
The assumed bulk temperatures and the heat transfer coefficients calculated for different regions of the piston along with temperature boundary conditions were indicated in Table

Table3 Convective boundary conditions

\begin{tabular}{|c|c|c|}
\hline Region & $\begin{array}{c}\text { Heat Transfer } \\
\text { Coefficient }\left(\mathrm{W} / \mathrm{mm}^{0} \mathrm{C}\right)\end{array}$ & $\begin{array}{c}\text { Bulk Temperature } \\
\left({ }^{\circ} \mathrm{C}\right)\end{array}$ \\
\hline A & 698 & 650 \\
\hline B & 470 & 500 \\
\hline C & 470 & 180 \\
\hline D & 470 & 170 \\
\hline E & 470 & 110 \\
\hline J & 900 & 95 \\
\hline I & 240 & 95 \\
\hline
\end{tabular}

Temperature boundary conditions

The temperature boundary conditions were applied at the piston and the oil ring regions.

Table4 Temperature boundary conditions

\begin{tabular}{|c|c|}
\hline Region & Temperature $\left({ }^{\circ} \mathrm{C}\right)$ \\
\hline F & 200 \\
\hline G & 180 \\
\hline H & 170 \\
\hline
\end{tabular}

Different regions of piston at which the thermal boundary conditions are to be applied as shown in the Figure

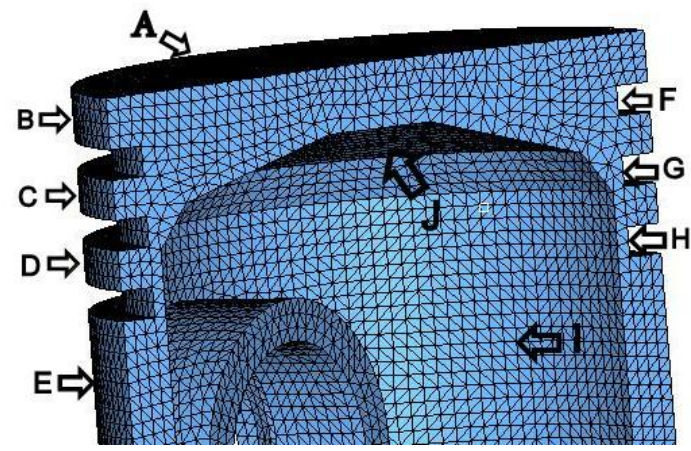

Fig.5 Model showing different regions to apply thermal boundary conditions

\subsection{Thermal Stress and structural analysis}

In case of thermal stress analysis, all the displacements at the piston pin region set to zero to act as boundary conditions. The displacement perpendicular to the piston surface was also set to zero i.e Uy is 0 because symmetric model was considered for analysis. The temperatures obtained from thermal analysis were also applied on to the piston to get thermal stresses. The boundary conditions applied. 


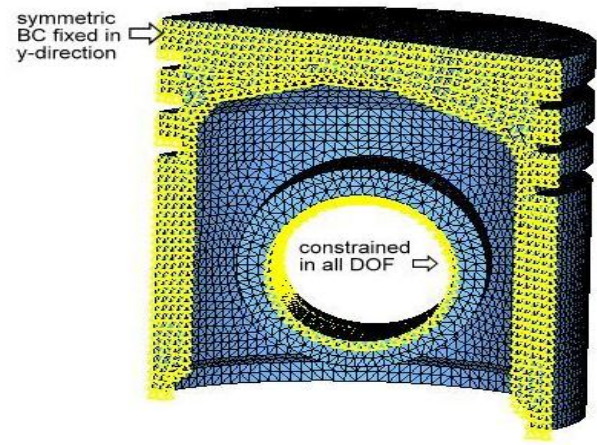

Fig.6 Boundary conditions for Structural stress analysis

In addition to the boundary conditions considered for thermal stress analysis instead of temperature, a pressure was applied on the crown and the inertia force was also applied to get the von-misses stresses. Boundary conditions applied for structural analysis are shown in figure.

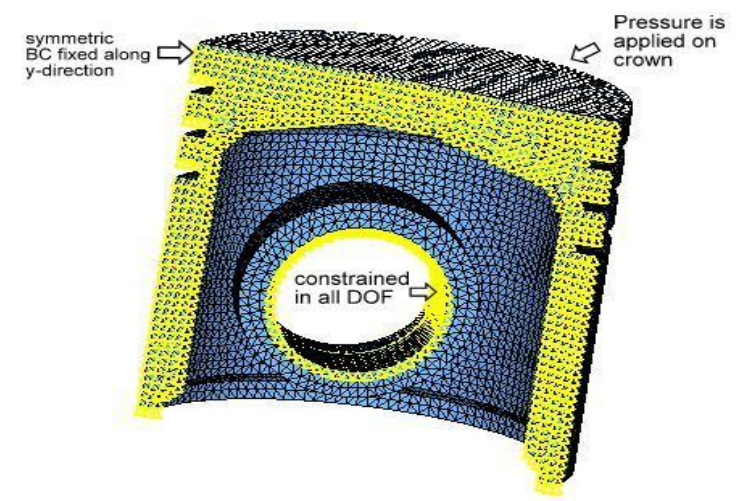

Fig.7 Boundary conditions for structural analysis

\subsection{Thermal analysis}

The meshed model was imported to ANSYS in .cdb format for carrying out the steady state thermal analysis. Element type selected is SOLID 90 and temperature related material properties like thermal conductivity etc are defined for Al-Si alloy, MgZrO3 and $\mathrm{NiCrAl}$ in the element attributes. The heat flow from piston to surroundings is assumed as convective mode of transfer. The convection boundary conditions along with the temperatures at the piston pin regions are applied on different regions as boundary conditions by calling the related entity sets that were created in hypermesh individually from the component manager. The solving of the problem was done. The results obtained after the solving can be viewed in the post processing tree. The final results display the distribution of temperatures on the surface of the piston crown.
Thermal Stress analysis

The thermal stresses have very high significance in deciding the efficient operation of a component. These are generated when changes in the dimensions that happen due to heat are restricted. This stress analysis can predict the displacements and the stresses that are caused due to expansion and contraction of the component. In this case, thermal stresses generated at the interface of the bond coatings, ceramic coatings and the base metal were studied. The stresses are generated at the interfaces due to the presence of different materials with each material possessing different properties. The procedure for thermal stress analysis is similar to the thermal analysis except the boundary conditions. In thermal stress analysis, the boundary conditions are the displacement constraints at the whole region in all DOF. The edges are constrained along normal direction because of symmetry model. Thermal stress analysis makes use of the temperatures obtained in thermal analysis and the element type is to be switched from thermal element to the structural element. SOLID 45 is the structural element chosen. The thermal result file (.rth) is read into this stress analysis to get the stress values due to temperatures. Finally, the plots for von-Mises stresses are obtained at the interfaces.

\section{Results and Discussions}

\subsection{Thermal Analysis}

The Thermal Stress Distribution on the surface of the piston for different coating thickness are shown below figures

The Thermal Stress Distribution for coated and uncoated piston models show that the thermal stress is maximum at the centre for uncoated model and at edges for the coated model. The Fig show that the thermal stress from centre along the length towards the edge for uncoated piston and sharply increases at the edges for the ceramic coatings. This rise in thermal stress at the ceramic coatings is due to the low thermal conductivity of ceramics. The maximum thermal stress for uncoated, $0.6 \mathrm{~mm}, 1.2 \mathrm{~mm}$ and $1.8 \mathrm{~mm}$ coating thickness are $145 \mathrm{MPa}, 215 \mathrm{MPa}, 308 \mathrm{MPa}, 370 \mathrm{MPa}$ respectively.

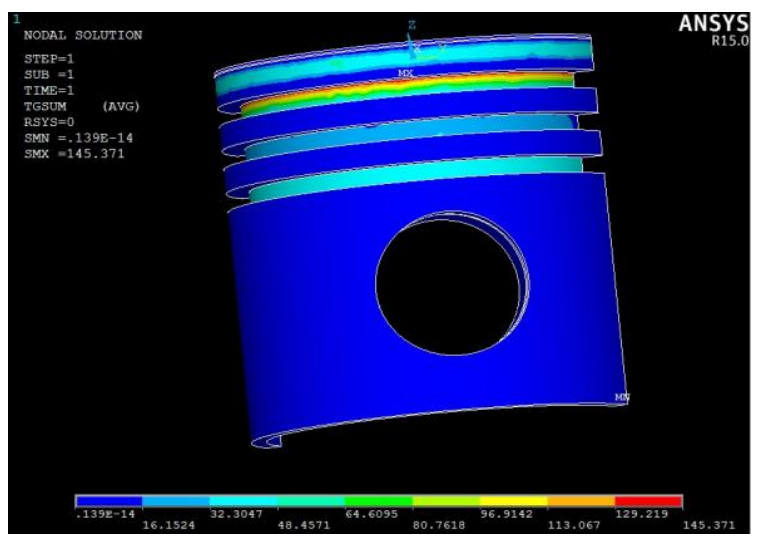

Fig.8 Temperature Distributions of Uncoated piston 


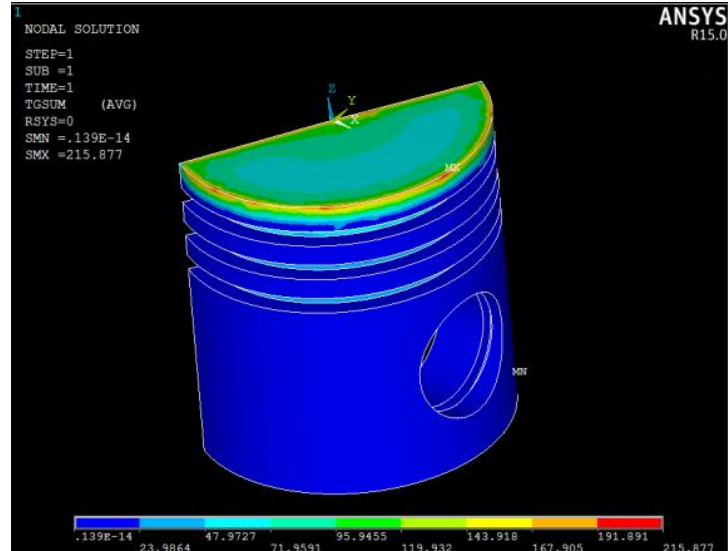

Fig.9 Thermal Stress Distribution of $0.6 \mathrm{~mm}$ coat

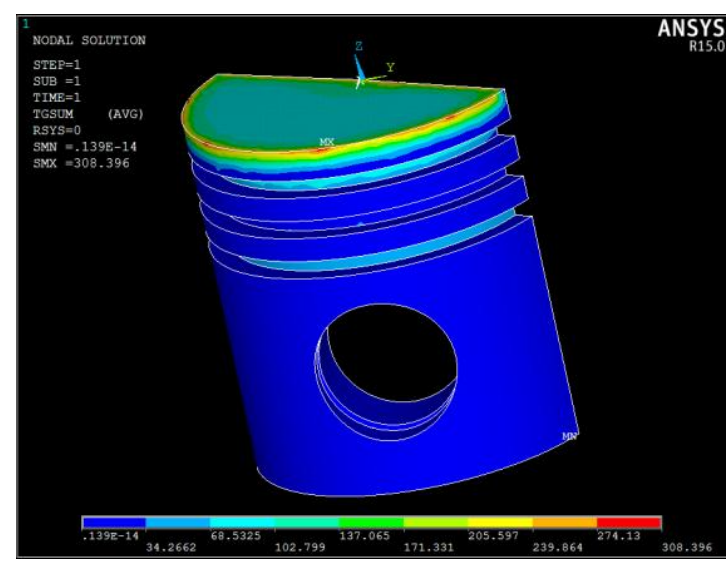

Fig.10 Thermal Stress Distribution of $1.2 \mathrm{~mm}$ coat

Table5 Maximum thermal stress values for ceramic coated pistons

\begin{tabular}{|c|c|}
\hline Coating thickness & Max. Stress(MPa) \\
\hline $1.8 . \mathrm{mm}$ & 370 \\
\hline $1.2 \mathrm{~mm}$ & 308 \\
\hline $0.6 \mathrm{~mm}$ & 215 \\
\hline
\end{tabular}

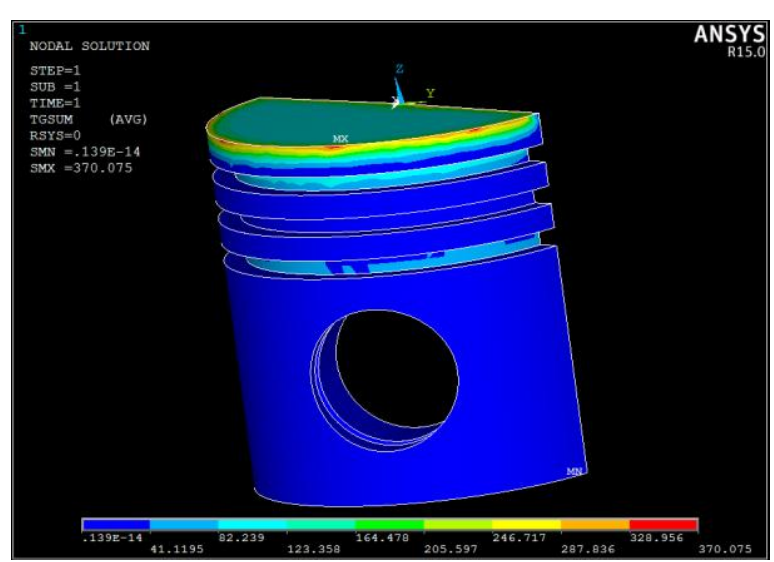

Fig.11 Thermal Stress Distribution of $1.8 \mathrm{~mm}$ coat

For the uncoated piston, the surface temperature varies slightly which goes on decreasing from centre to the edges. In case of coated pistons, the surface temperatures are same as uncoated piston up to the ceramic coated region. As it approaches the coated region, the temperatures increases abruptly and the variation is not linear. With the increase in the coating thickness, thermal conductivity of the ceramics will be low. Due to the lower conductivity, the temperature at the ceramic coated region increases. From the plot it can be seen that the maximum temperature is for the 1.8 coating thickness followed by $1.2 \mathrm{~mm}$ and $0.6 \mathrm{~mm}$ thickness. For the uncoated piston the maximum temperature is $145^{\circ} \mathrm{C}$.

\subsection{Structural Analysis of Piston}

For the structural analysis, a uniform pressure of 1.3 MPa is applied on the crown surface.

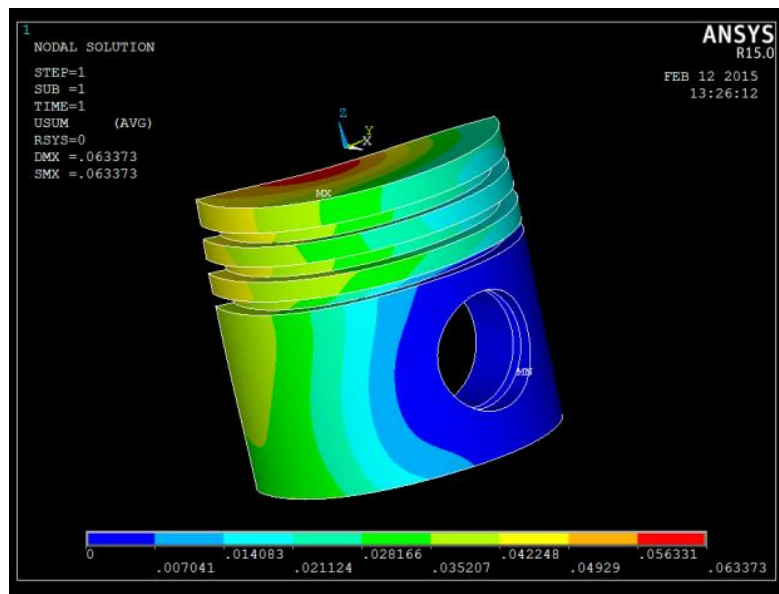

Fig.12 Displacement for uncoated piston crown

Table 6 Maximum Displacement values for ceramic coated pistons

\begin{tabular}{|c|c|}
\hline Coating thickness & Max. Displacement $(\mathrm{mm})$ \\
\hline $1.8 . \mathrm{mm}$ & 0.0509 \\
\hline $1.2 \mathrm{~mm}$ & 0.0602 \\
\hline $0.6 \mathrm{~mm}$ & 0.0724 \\
\hline
\end{tabular}

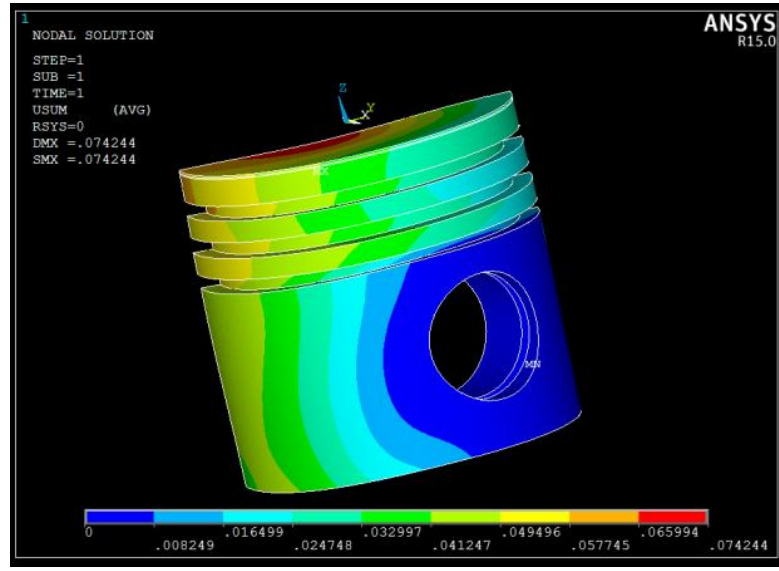

Fig.13 Displacement for $0.6 \mathrm{~mm}$ coat 


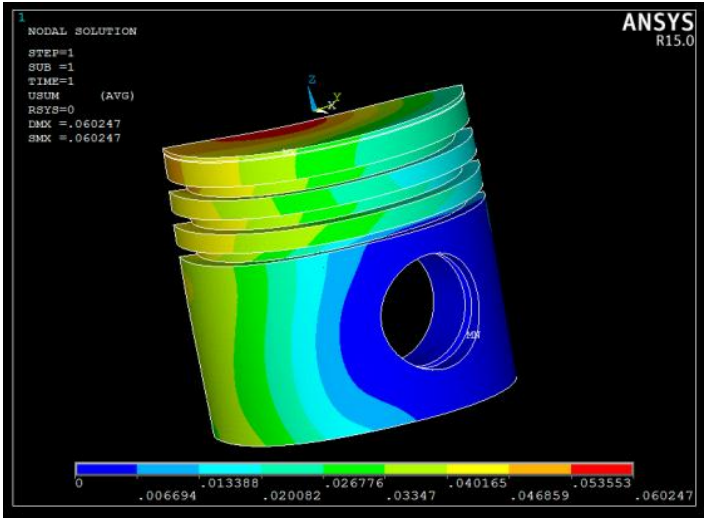

Fig.14 Displacement plot for $1.2 \mathrm{~mm}$ coat

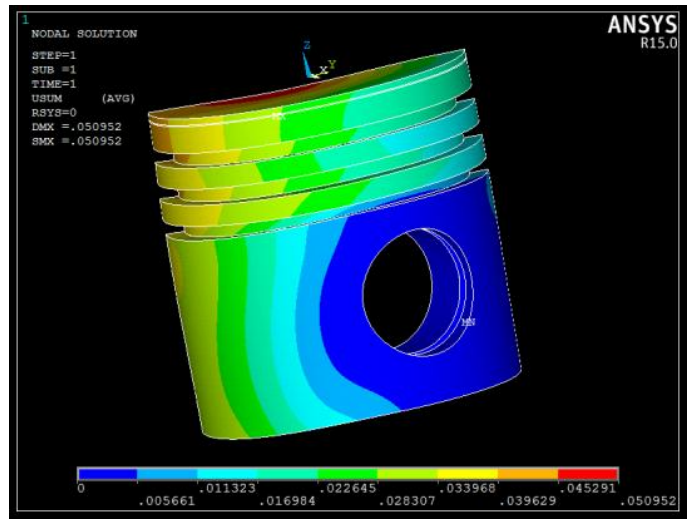

Fig.15 Displacement plot for $1.8 \mathrm{~mm}$ coat

Displacement at the centre of crown is maximum. As increase in thickness of coating displacement decreases. Maximum displacement is $0.0724 \mathrm{~mm}$ at $0.6 \mathrm{~mm}$ thickness of coating.

\subsection{Von-mises stress distribution}

At the crown surface the variation of von-Mises stress distribution for coated and uncoated surfaces are as shown below

Similar to the temperature plot, the von-Mises stresses of all pistons were similar up to the ceramic coating. As it approaches the ceramic coat region, the stresses increase sharply for the coated pistons. The stress will be maximum for the low coating thickness and goes on decreasing with the increase in the coating thickness. The $0.6 \mathrm{~mm}$ coated thickness has maximum stress compared to other coating thickness. Maximum value of von-Mises stress is $170 \mathrm{MPa}$ for the $0.6 \mathrm{~mm}$ thickness. The stresses generated is more in case of 0.6 $\mathrm{mm}$ coated piston because of low thickness compared to $1.2 \mathrm{~mm}$ and $1.8 \mathrm{~mm}$.

Table 6 Maximum values of von-Mises stress

\begin{tabular}{|c|c|}
\hline Coating Thickness & Max. von-Mises stress(MPa) \\
\hline 1.8 & 122 \\
\hline 1.2 & 141 \\
\hline 0.6 & 170 \\
\hline
\end{tabular}

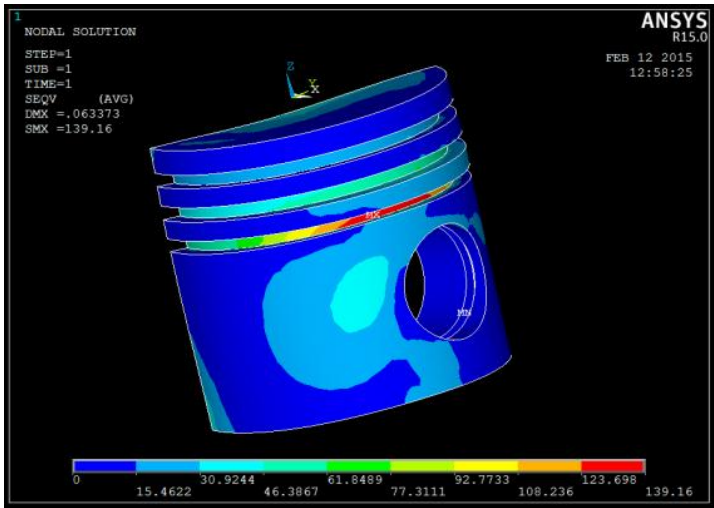

Fig.16 Von-mises stress plot for uncoated piston

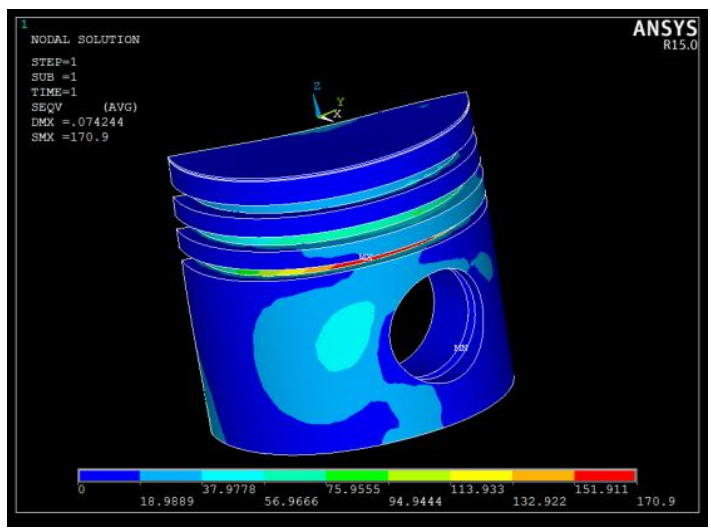

Fig.17 Von-mises stress plot for $0.6 \mathrm{~mm}$ coat

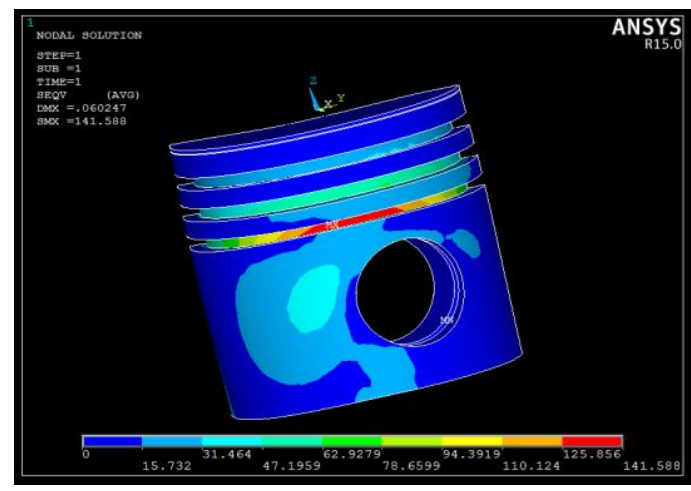

Fig.18 Von-mises stress plot for $1.2 \mathrm{~mm}$ coat

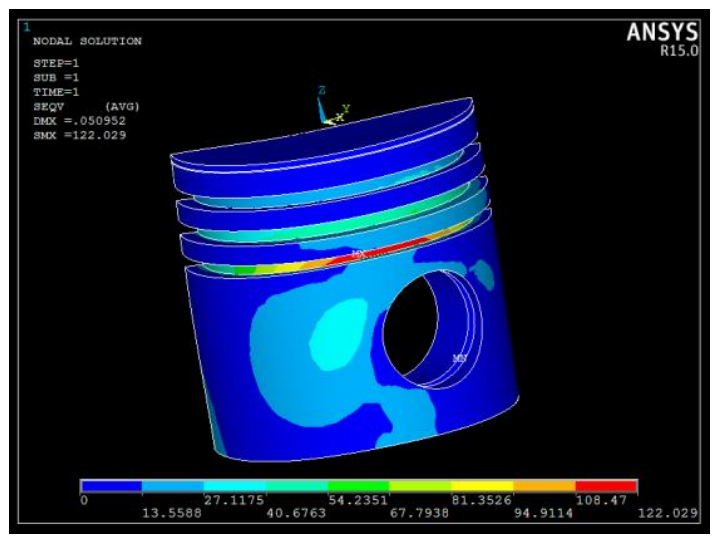

Fig.19 Von-mises stress plot for $1.8 \mathrm{~mm}$ coat 


\section{Conclusions}

1) It can be concluded that the Thermal Stress Distribution is a function of coating thickness. With increase in thickness, the maximum temperature increases on piston crown.

2) The von-Mises stress decreases with the increase in the coating thickness on the surface of the piston.

\section{References}

F.S. Silva (2004), Fatigue on engine pistons - A compendium of case studies, science direct, Engineering Failure Analysis 13 (2006) 480-492

Ekrem Buyukkaya, Muhammet Cerit, (2007) Thermal analysis of a ceramic coating diesel engine piston using 3-D finite element method, science direct, Surface \& Coatings Technology 202 (2007) 398-402
Adnan Parlak, Idris Cesur,Vezir Ayhan, Barış Boru and Görkem Kökkülünk,(2014) Comparison for Performance and Exhaust Emissions of Steam Injected and Thermal Barrier Layer (TBL) Coated Piston Spark Ignition Engine ISBN: 978-1-61804-221-7.

Kuldeep Singh, Dr. O.P. Jakhar, (2014) The Behavior of Temperature on Insulated (MgZrO3) Diesel Engine Piston With ANSYS, ISSN 2250-2459.

Vikram A. Mistry, 2 Dipak C. Gosai, 3 Dr. H.J. Nagarsheth,(2014), Temperature Distribution Analysis of MgZrO3 Coated and Conventional IC Engine Components using FEM, Volume 2, Issue 2 ISSN 2321-9939

Dipak Kumar, K.N.Pandey, (2014), Study on Thermal Fatigue Behavior of Plasma Sprayed Yttria-Zirconia Thermal Barrier Coatings (Tbcs) Systems on Aluminium Alloy, Proceedings of Irf International Conference, 23rd February 2014, Pune, India. Isbn: 978-93-82702-61-0. 